\title{
The effect of iron corrosion in cast iron pipes on the microbiological quality of drinking water: A laboratory and field investigation
}

\author{
Thilini S. Munasinghe ${ }^{1, *}$, Charmalie L. Abayasekara ${ }^{1}$, Asoka Jayawardana ${ }^{2}$ and \\ Rohana Chandrajith $^{3}$
}

${ }^{1}$ Department of Botany, Faculty of Science, University of Peradeniya, Peradeniya, Sri Lanka

${ }^{2}$ National Water Supply and Drainage Board, Sarasavi Uyana, Peradeniya, Sri Lanka

${ }^{3}$ Department of Geology, Faculty of Science, University of Peradeniya, Peradeniya, Sri Lanka

\begin{abstract}
Iron pipelines are commonly used in old drinking water distribution systems, adding rust to pipe-borne water. Chlorine added to water for disinfection could react with iron that leaches from these iron pipelines, thereby reducing available free chlorine for disinfection. The consumption of dissolved chlorine by iron and consequent effects on the microbiological quality of drinking water were investigated, by spiking Serratia marcescens and Escherichia coli into different known mixtures of $\mathrm{Fe}^{2+}$ and chlorine. Twenty seven water samples were collected from three water supply systems at the University of Peradeniya, Sri Lanka and investigated for its iron content, residual chlorine and microbial quality. The selected water distribution system is 60 years old and is corroded to a large extent, adding rust to the pipe-bone water. The results indicated that the rate of chlorine consumption in water was directly proportional to the content of $\mathrm{Fe}^{2+}$ ion in water. The $\mathrm{Fe}^{2+}$ concentration in drinking water in iron pipelines ranged from $<0.01$ to $0.64 \mathrm{mg} / \mathrm{L}$, while the desired residual chlorine levels were not obtained. Both total and fecal coliforms were detected in some samples indicating that the disinfection was not effective due to chlorine consumption in the distribution system. It was also observed that a high level of ferrous ions in water was inhibitory to microorganisms by forming iron-bacteria clumps in water.
\end{abstract}

Keywords: cast iron, corrosion, disinfection, drinking water, free chlorine, microbiological quality.

\section{INTRODUCTION}

Providing safe drinking water is one of the important millennium development goals set by the United Nations since 783 million people of the global population still lack safe drinking water (UN, 2012). Even though some populations have easy access to potable water through pipe borne supply systems, the quality of such water is not satisfactory in most cases, particularly in developing countries. From among many potable water quality parameters, microbiological quality is one of the important parameters that should be seriously considered. Maintenance of the microbiological quality of pipe-borne drinking water is accomplished by various disinfectants. For disinfection, chlorine and chloramine are used very commonly, in countries where more expensive non-chemical disinfection methods such as ozonation, UVtreatments cannot be easily adopted. Due to low cost, stability, and effectiveness, free chlorine is the most commonly used disinfectant worldwide. However, chlorine and chloramine can decay when treated water moves through distribution systems (Rossman, 2006). In water distribution systems, the free chlorine residual level in excess of $0.2 \mathrm{mg} / \mathrm{L}$ should be maintained to reduce further microbial contamination (Al-Jasser, 2007). Several studies indicated possible negative effects of disinfections particularly on biofilm bacteria due to corrosion of metal pipe lines (LeChevallier et al., 1993). Since most of the old water distribution systems in cities particularly in developing countries are made up of iron pipelines, this has to be considered very seriously. Such old, unlined cast iron pipe lines add iron oxides to water due to internal corrosions that drastically affect the water quality. The iron rust mixes with water in distribution and could react with chlorine, chloramines and chlorine dioxide adversely affects the disinfection processes and reduces the quality of drinking water. Chlorine and related disinfection compounds also increase the corrosion of metallic distribution systems since they are strong oxidizers, releasing dissolved iron into the water. Usually free chlorine quickly converts to an equilibrium mixture of chlorine, hypochlorous acid ( $\mathrm{HOCl})$ and, 
hydrochloric acid $(\mathrm{HCl})$, in such a system in which the speciation depends on the $\mathrm{pH}$ of water. Free chlorine can therefore oxidize ferrous ions forming ferric ions as given below.

$\mathrm{Cl}_{2}+\mathrm{H}_{2} \mathrm{O} \leftrightharpoons \mathrm{HOCl}+\mathrm{HCl}$

$2 \mathrm{Fe}^{2+}+\mathrm{HOCl}+\mathrm{H}^{+} \rightarrow 2 \mathrm{Fe}^{3+}+\mathrm{Cl}^{-}+\mathrm{H}_{2} \mathrm{O} \ldots \ldots$

$6 \mathrm{Fe}^{2+}+3 \mathrm{ClO}^{-}+3 \mathrm{H}_{2} \mathrm{O} \rightarrow 2 \mathrm{Fe}^{3+}+\mathrm{Cl}^{-}+2 \mathrm{OH}^{-}$.

The consumption of free chlorine in water reduces the effectiveness of the disinfection process. Therefore, the main objective of the current study was to evaluate the impact of iron corrosion in the disinfection process of a castiron water distribution system. Accordingly, the variation of free chlorine and microbial quality in an iron pipe system was investigated. A laboratory simulated study was conducted to investigate the effect of dissolved iron on the residual chlorine content and on microbial contents.

\section{MATERIALS AND METHODS}

Effects of dissolve iron on the residual chlorine content in water were studied as a batch experiment, adding known concentrations of free chlorine dilutions to a series of ferrous standards. The ferrous ion content and free chlorine content in all resulting solutions were determined immediately and three replicates were carried out for each experiment. Residual chlorine was measured using N, N-diethyl-1,4phenylenediamine (DPD) method in which the absorption was measured using Hach DR 2700 spectrophotometer. Atomic Absorption Spectrophotometer (Varian 240FS) was used to analyze the total iron content. The standard ferrous solution was prepared using $\left(\mathrm{NH}_{4}\right)_{2} \mathrm{Fe}$ $\left(\mathrm{SO}_{4}\right)_{2} \cdot 6 \mathrm{H}_{2} \mathrm{O}$ while free chlorine solutions were prepared using sodium dichloroisocyanurate tablets (Medentech Ltd., Ireland). For microbiological quality investigations, nutrient agar (Himedia, India) and Mueller Hinton agar (Oxoid, UK) were used as the culturing media. MEndo (Himedia, India) and MFc (Himedia, India) media were used for the identification and enumeration of total coliforms and fecal coliforms, respectively. Brilliant Green Lactose Bile broth (Oxoid, UK) was used for confirmation tests. Aseptic conditions were strictly maintained throughout the bacteriological analysis.
Verification of the nature of the reaction between free chlorine and ferrous ions in water was tested by preparing a ferrous dilution series, and free chlorine dilution series, and subsequently adding known amounts of free chlorine and ferrous ions to the above dilution series, respectively. Effectiveness of chlorine in water on inhibition of total and fecal coliforms in the presence of iron was investigated under laboratory conditions. Fresh bacterial cultures of total and fecal coliforms were used in all experimental setups. For total coliforms, $S$. marcescens (NCTC 2446) and for fecal coliforms, E. coli (NTCC 7362) was used. The stock culture and the working culture of $S$. marcescens and E. coli were prepared by fresh inoculums, sub-cultured on nutrient agar plates and incubated at $37{ }^{\circ} \mathrm{C}$ for 24 hours. Standard suspensions of $S$. marcescens and E. coli (containing $10^{8} \mathrm{CFU} / \mathrm{ml}$ of bacterial cells) were prepared by mixing fresh inoculums of bacteria in sterilized deionized water. Both standards were standardized using McFarland 0.5 Standard Solution (Andrews, 2001). Standard bacterial suspensions containing $10^{4} \mathrm{CFU} / \mathrm{ml}$ of $S$. marcescens and $10^{4} \mathrm{CFU} / \mathrm{ml}$ of $E$. coli were prepared by mixing $10 \mu \mathrm{l}$ of the above standard bacterial suspensions $\left(10^{8} \mathrm{CFU} / \mathrm{ml}\right)$ with $100 \mathrm{ml}$ of sterilized de ionized water separately for batchexperiments. Each bacterial suspensions $\left(0.1 \mathrm{ml}-10^{4} \mathrm{CFU} / \mathrm{ml}\right.$ of $S$. marcescens and $10^{4}$ $\mathrm{CFU} / \mathrm{ml}$ of E. coli) was spiked into $10 \mathrm{ml}$ of test solutions containing a known amount of ferrous ions, residual chlorine and a mixture of known ferrous and chlorine, separately. The ferrous ion and free chlorine contents in all resulting solutions were measured immediately after the experiment. Available $S$. marcescens and E. coli in test solutions were enumerated by using the membrane filtration technique with positive (with $S$. marcescens and E. coli) and negative (with sterilized deionized water) controls.

A 60 year old drinking water distribution system with iron pipelines was selected for the field level investigation, viz; University of Peradeniya one of the oldest state universities in Sri Lanka. Three separate water purification systems (located at Gatambe [managed by the Kandy Municipal Council], Meewathura and near the University Piggery [managed by the National Drainage and Water Board and University authorities]) supply drinking water to this distribution system which consists of highly corroded pipe lines. Representative samples from 
27 locations including the staring points and different domestic end points were collected in triplicate. Dissolved irons, free chlorine, total and fecal coliforms were determined in all samples within a few hours of sampling. Acidified samples were collected for the dissolved iron determinations. Colonies from positive isolates from water samples were inoculated in nutrient agar plates and incubated at $37{ }^{\circ} \mathrm{C}$ for 24 hours. For the conformation of bacterial samples from cultures were inoculated into two tubes containing brilliant green lactose bile broth with Durham tubes. One set of tubes were incubated at $37{ }^{\circ} \mathrm{C}$ for 24 hours and the other set at $44.5{ }^{\circ} \mathrm{C}$ for 48 hours to confirm the presence of total and fecal coliforms, respectively.

\section{RESULTS AND DISCUSSION}

\section{Effects of dissolved iron on residual chlorine}

The variation of residual chlorine in the solution at different constant ferrous ion levels (1.0, 5.0 and $10.0 \mathrm{mg} / \mathrm{L} \mathrm{Fe}^{2+}$ ) are shown in figure 1. It clearly indicates that even $1.0 \mathrm{mg} / \mathrm{L}$ of ferrous affects the residual chlorine in the solution (e.g. Initial $10.0 \mathrm{mg} / \mathrm{L}$ of chlorine was reduced to 5.0 $\mathrm{mg} / \mathrm{L}$ of chlorine at $1 \mathrm{mg} / \mathrm{L}$ of $\mathrm{Fe}^{2+}$ ). Residual chlorine was reduced to undetectable levels at $5.0 \mathrm{mg} / \mathrm{L}$ and $10.0 \mathrm{mg} / \mathrm{L}$ of ferrous ions. It is evident that as the ferrous iron concentration increases, available chlorine in the solution decreases drastically. Therefore, chlorine available for microbial disinfection is limited.
Rahman and Gagnon (2014) also showed a rapid reaction between ferrous ions (which are released from iron corrosion), and chlorine which is added as a disinfectant. Our experimental results also revealed a noteworthy effect of $\mathrm{Fe}^{2+}$ concentration on the reduction of residual chlorine. Even a lower amount of ferrous ions are able to diminish almost all residual chlorine in water. Free chlorine can also be consumed by dissolved organic compounds in water and also oxidizes internal walls of iron pipes. It generally reacts firstly with the biomass in water and then with the materials (Frateur et al., 1999). Due to the reaction with residual chlorine, ferrous ions oxidize to ferric form and precipitated as ferric hydroxide as given in equation 3 .

\section{Effects of dissolved iron and residual chlorine on microbial inhibition}

It was observed that both $S$. marcescens and $E$. coli counts decreased with the increasing residual chlorine concentration (Figures 2 and 3). However, a decrease in microbial counts was also observed with increased levels of iron. This may be due to clumping of microbes with available iron. Yang et al. (2013) reports that ferric hydroxide acts as a coagulant that removes microorganisms from drinking water. As indicated by the current study, $\mathrm{Fe}^{2+}$ in water was above the desirable levels $(0.3 \mathrm{mg} / \mathrm{L})$ in drinking water and the inhibition of microorganisms was maximum at the highest level of $\mathrm{Fe}^{2+}(3 \mathrm{mg} / \mathrm{L})$.

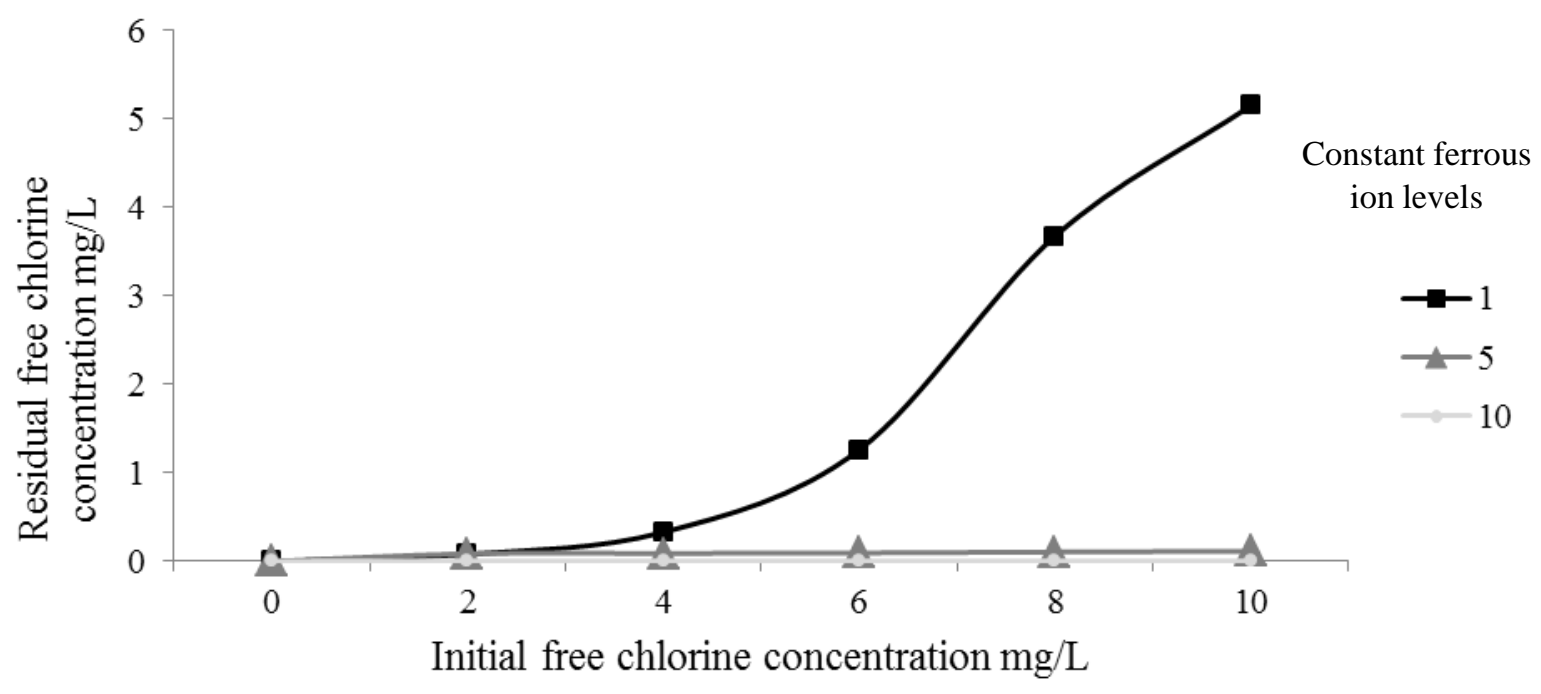

Figure 1: Residual free chlorine levels at constant initial ferrous ion concentrations of 1,5 and $10 \mathrm{mg} / \mathrm{L}$. 


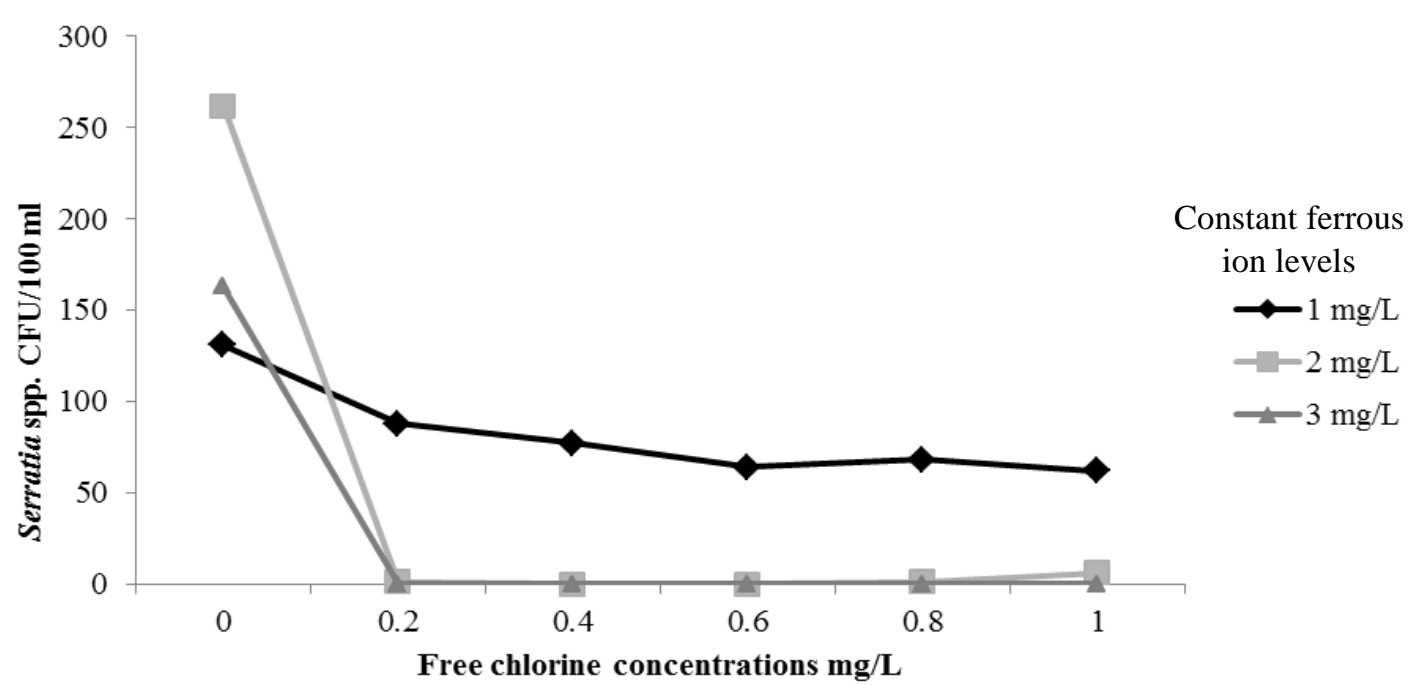

Figure 2: Inhibition of $S$. marcescens at different $\mathrm{Cl}_{2}$ concentrations under constant ferrous ions concentrations of 1,2 and 3 $\mathrm{mg} / \mathrm{L}$.

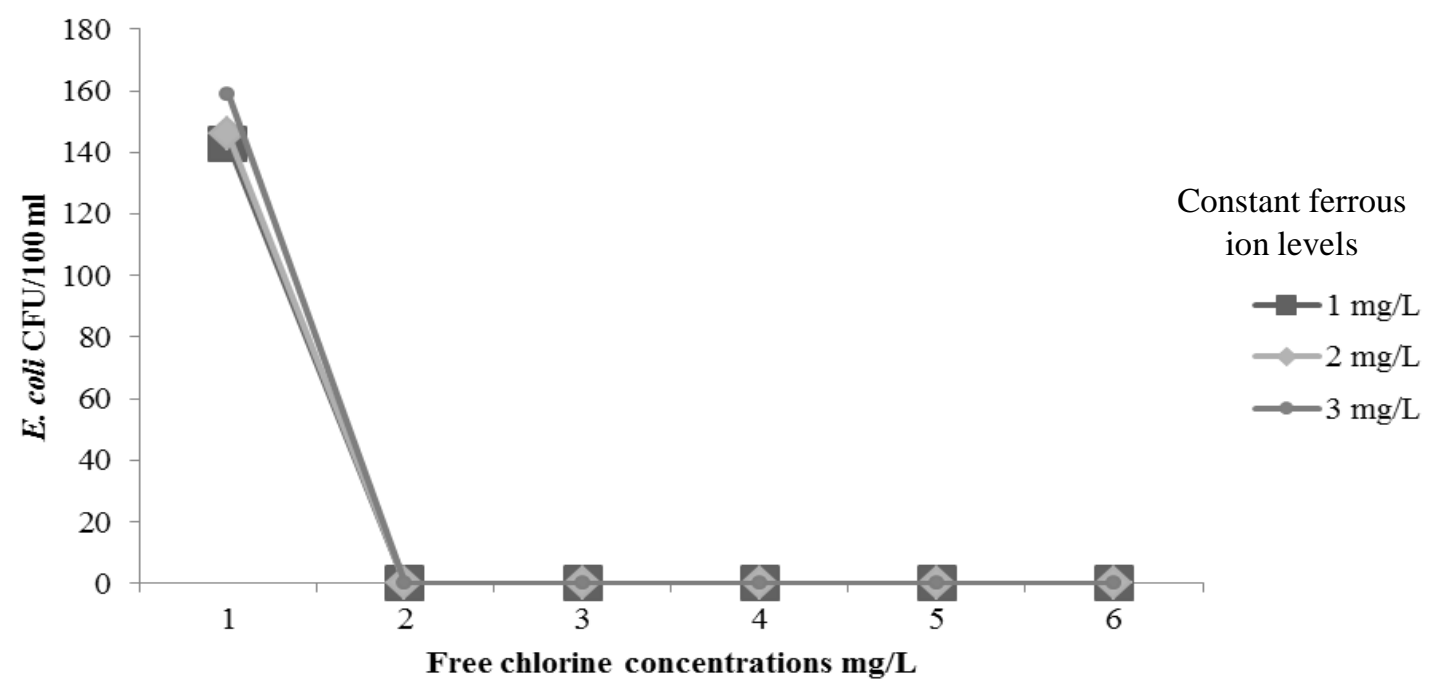

Figure 3: Inhibition of E.coli at different $\mathrm{Cl}_{2}$ concentrations under constant ferrous ions concentrations of 1, 2 and $3 \mathrm{mg} / \mathrm{L}$.

Iron can be naturally present in water in soluble forms as ferrous ions (bivalent iron dissolved in form of $\mathrm{Fe}^{2+}$ ) or complexed forms like the ferric ion [trivalent ion in form of $\mathrm{Fe}^{3+}$ in the precipitate $\left.\mathrm{Fe}(\mathrm{OH})_{3}\right]($ Chaturvedi and Dave, 2012). However, certain bacteria can clog with iron precipitates and could be removed from the drinking water. Clogging/clumping can occur if ferrous bicarbonates are present in water. On the other hand, certain bacteria thrive on elevated levels of iron, and may adhere to pipe surfaces as a suitable habitat (Chaturvedi and Dave, 2012).

A higher inhibition was observed for $E$. coli when compared to $S$. marcescens at different chlorine levels when the $\mathrm{Fe}^{2+}$ level was kept constant. Both E. coli and S. marcescens are Gram negative motile bacteria, and probably there is more clumping of E.coli with iron precipitates when compared to $S$. marcescens. In addition the differences in siderophore production of E.coli and S. marcescens may have an effect in their tolerance to different chlorine concentrations when the $\mathrm{Fe}^{2+}$ level is constant (Letoffe et al., 1998).

\section{Field level investigation}

The effect of iron pipe corrosion on the residual chlorine in water at the University of Peradeniya, was investigated using 27 representative samples from the three distribution systems, including the starting points and different domestic end points. 
It was observed that the $\mathrm{Fe}^{2+}$ concentration in these water distribution systems ranged from $<0.01 \mathrm{mg} / \mathrm{L}$ to $0.64 \mathrm{mg} / \mathrm{L}$ with an average of 0.08 $\mathrm{mg} / \mathrm{L}$. However, only two samples showed dissolve iron levels that exceeded the desirable limit $(0.3 \mathrm{mg} / \mathrm{L})$ set for drinking water by the WHO (WHO, 2012). Among the water samples, total coliforms were detected in six samples, while fecal coliforms were detected in one sample, indicating that the disinfection processes is not effective. From among investigated samples, only two samples had the desirable levels of residual chlorine (0.2 mg/L) (Figure 4).

In order to maintain the required residual chlorine levels at the point of consumption, higher chlorine levels are added during water purification. However, this study indicated that sufficient residual chlorine levels are not available for disinfection during distribution. It is possible that the available chlorine in iron pipelines, has been used up by $\mathrm{Fe}^{2+}$ ions, and may have also been used up to combat any microbial contamination along the distribution line through seepage. This may reduce the amount of available chlorine all through the distribution system. Recent studies have documented that the rapid dissipation of the disinfectant in drinking water, promotes regrowth of microorganisms, some of which are potential opportunistic pathogens (Jjemba et al., 2010). Regrowth of microorganisms has been highlighted as the most likely source of organisms detected near the point of use in water distribution systems (Muyima, and Ngcakani, 1998). Therefore, the maintenance of desirable free chlorine levels throughout the water distribution systems is crucial. Although much attention has been given to the quality of drinking water at treatment plants, water quality can be degraded by the time the water reaches the point of use (Wang et al., 2014).

On the other hand, even though the desirable levels of $\mathrm{Cl}_{2}$ were not met in most water samples, total and fecal coliforms were not present in these samples. This may be due to effective disinfection at the beginning of the water distribution systems and probably no contamination or oxidation of $\mathrm{Fe}^{2+}$ by available chlorine in the water. The maintenance of a desirable residual free chlorine level is vital as there can be contamination through seepage.

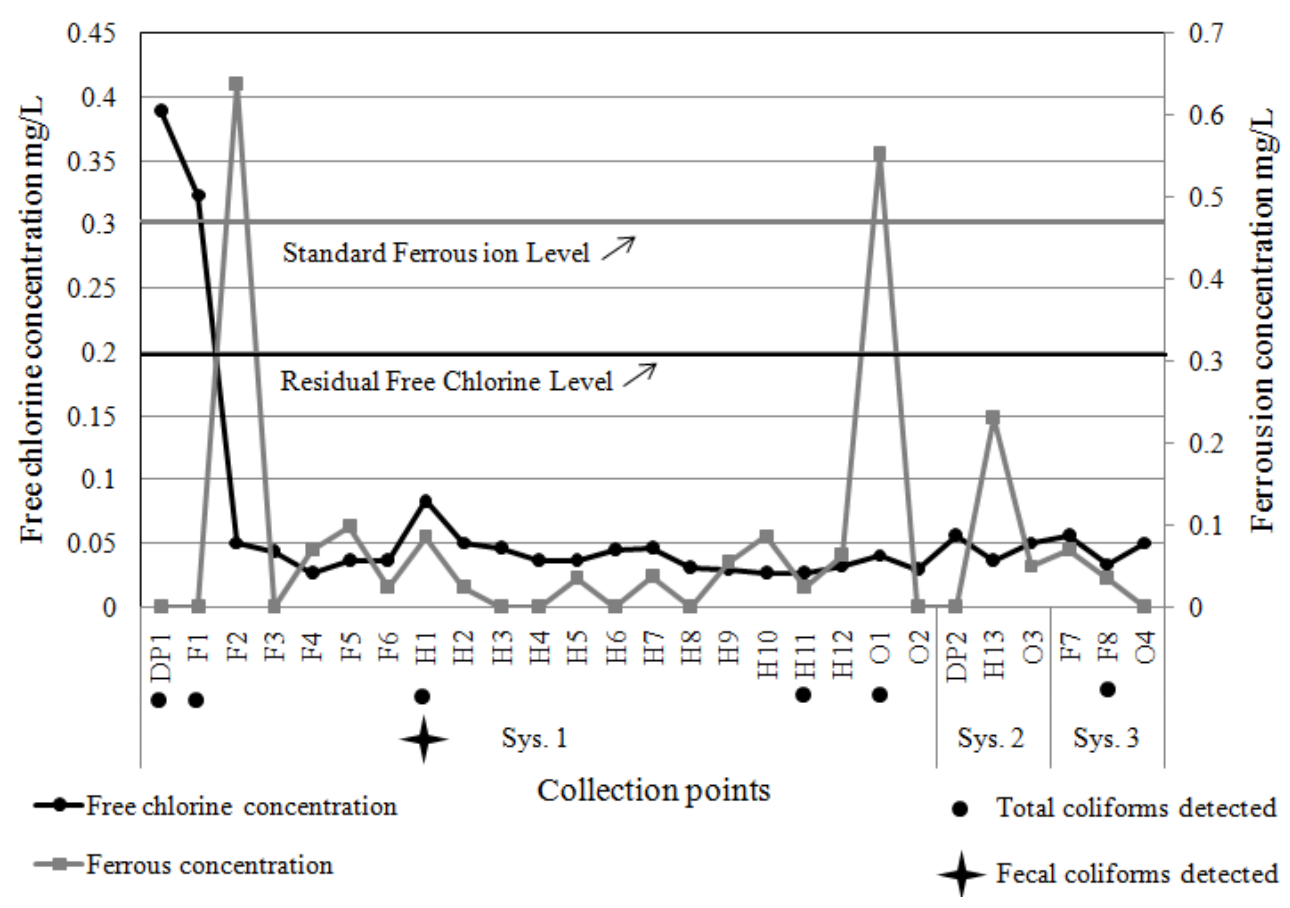

Figure 4: Average free chlorine, ferrous ion concentrations, and the presence of total and fecal coliforms in different samples from the three water distribution systems. Each data point is an average of 3 trials carried out at different times. $(\mathrm{n}=27)$. DP - Distribution points, F- Faculties of study, $\mathrm{H}$ - Halls of residence, $\mathrm{O}$ - Other points

System 1 - Meewathura System, 2 - near the University Piggery, System 3 - at Gatambe [Kandy Municipal Council. 
Iron corrosion can also adversely affect the drinking water quality causing reddish colored water with high turbidity (Sarin et al., 2004). The release of soluble or particulate iron corrosion byproducts to the water also decreases the aesthetic quality (Lytle et al., 2004). High levels of ferrous ion in drinking water can cause adverse health effects such as kidney diseases and tooth problems (Jjemba et al., 2010). The effects of toxic doses of iron include depression, rapid and shallow respiration, coma, convulsions, respiratory failure, and cardiac arrest.

Further, several trace impurities (i.e. metals, organic compounds and microorganisms) adsorb onto iron surfaces may also cause adverse health effects (Lytle and Snoeyink, 2002). In the current study, two water samples showed iron levels of $0.64 \mathrm{mg} / \mathrm{L}$ and $0.55 \mathrm{mg} / \mathrm{L}$ that are above the desired level of WHO $(0.3 \mathrm{mg} / \mathrm{L})$.

\section{CONCLUSION}

According to the laboratory study, there was a rapid reaction between iron and free chlorine added to water. Microbial inhibition was higher at elevated levels of ferrous ions, though a high level of iron is not desirable in drinking water. The field study revealed that desirable residual chlorine levels were not maintained throughout the distribution systems at the University of Peradeniya. Total coliforms were detected in six water samples, while fecal coliforms were detected in one water sample, confirming that the water is not safe for drinking purposes according to Sri Lanka standards and WHO guidelines. The chlorine added into water as a disinfectant rapidly reacts with iron that leaches from corroded iron pipelines, resulting in insufficient chlorine in water for the complete disinfection of microorganisms.

\section{REFERENCES}

Al-Jasser, A.O., 2007. Chlorine decay in drinkingwater transmission and distribution systems: Pipe service age effect. Water Research 41(2), pp.387396.

Andrews, J.M., 2001. Determination of minimum inhibitory concentrations. Journal of antimicrobial Chemotherapy 48 (suppl 1), pp.516.

Chaturvedi, S. and Dave, P.N., 2012.Removal of iron for safe drinking water. Desalination 303, pp.111.

Frateur, I., Deslouis, C., Kiene, L., Levi, Y. and Tribollet, B., 1999. Free chlorine consumption induced by cast iron corrosion in drinking water distribution systems. Water Research 33(8), pp.1781-1790.

Jjemba, P.K., Weinrich, L.A., Cheng, W., Giraldo, E. and LeChevallier, M.W., 2010. Regrowth of potential opportunistic pathogens and algae in reclaimed-water distribution systems. Applied and environmental microbiology 76(13), pp.4169-4178.

LeChevallier, M.W., Lowry, C.D., Lee, R.G. and Gibbon, D.L., 1993. Examining the relationship between iron corrosion and the disinfection of biofilm bacteria. Journal (American Water Works Association), pp.111-123.

Létoffé, S., Redeker, V. and Wandersman, C., 1998. Isolation and characterization of an extracellular haem-binding protein from Pseudomonas aeruginosa that shares function and sequence similarities with the Serratiamarcescens has Ahaemophore. Molecular microbiology 28(6), pp.1223-1234.

Lytle, D.A., Magnuson, M.L. and Snoeyink, V.L., 2004. Effect of oxidants on the properties of $\mathrm{Fe}$ (III) particles and suspensions formed from the oxidation of $\mathrm{Fe}$ (II). Journal (American Water Works Association) 96(8), pp.112-124.

Lytle, D.A. and Snoeyink, V.L., 2002. Effect of orthoand polyphosphates on the properties of iron particles and suspensions. Journal (American Water Works Association) 94(10), pp.87-99.

Muyima, N.Y.O. and Ngcakani, F., 1998.Indicator bacteria and regrowth potential of the drinking water in Alice, Eastern Cape. WATER SAPRETORIA-, 24, pp.29-34.

Rahman, M. S., and Gagnon, G. A., (2014) "Benchscale evaluation of drinking water treatment parameters on iron particles and water quality." Water research vol. 48 pp. 137-147.

Rossman, L.A., 2006. The effect of advanced treatment on chlorine decay in metallic pipes. Water Research 40(13), pp.2493-2502.

Sarin, P., Snoeyink, V. L., Bebee, J., and Jim, K. K., (2004) "Iron release from corroded iron pipes in drinking water distribution systems: effect of dissolved oxygen." Water research vol. 38 pp. 1259-1269.

Wang, H., Hu, C. and Hu, X., 2014.Effects of combined UV and chlorine disinfection on corrosion and water quality within reclaimed water distribution systems. Engineering Failure Analysis 39, pp.12-20.

United Nations - Water. Un.org. N.p., 2017. Web. 3 Apr. 2017.

WHO. Guidelines for drinking water quality, 2 ed. Geneva: World Health Organization, 2012.

Yang, X., Guo, W., Zhang, X., Chen, F., Ye, T. and Liu, W., 2013.Formation of disinfection byproducts after pre-oxidation with chlorine dioxide or ferrate. Water research 47(15), pp.5856-5864. 